\section{(6) OPEN ACCESS}

\title{
Are we failing to provide adequate rescue medication to children at risk of prolonged convulsive seizures in schools?
}

\author{
J Helen Cross, ${ }^{1,2}$ Suzanne Wait, ${ }^{3}$ Alexis Arzimanoglou, ${ }^{4}$ Ettore Beghi, ${ }^{5}$ \\ Christine Bennett, ${ }^{6}$ Lieven Lagae, ${ }^{7}$ Janet Mifsud, ${ }^{8}$ Dieter Schmidt, ${ }^{9}$ Gordon Harvey ${ }^{10}$
}

For numbered affiliations see end of article.

\section{Correspondence to}

Professor J Helen Cross, UCL, Institute of Child Health, Great Ormond Street Hospital NHS Foundation Trust, The

Neurosciences Unit, 4/5 Long Yard, London WC1N 3LU, UK; h.cross@ucl.ac.uk

Received 22 March 2013 Revised 9 July 2013 Accepted 10 July 2013 Published Online First 30 July 2013

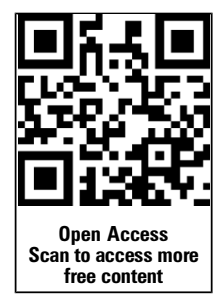

To cite: Cross JH, Wait $\mathrm{S}$, Arzimanoglou A, et al. Arch Dis Child 2013:98: 777-780.

\section{ABSTRACT}

Objective This paper explores the issues that arise from the discussion of administering rescue medication to children who experience prolonged convulsive seizures in mainstream schools in the UK.

Situation analysis Current guidelines recommend immediate treatment of children with such seizures (defined as seizures lasting more than $5 \mathrm{~min}$ ) to prevent progression to status epilepticus and neurological morbidity. As children are unconscious during prolonged convulsive seizures, whether or not they receive their treatment in time depends on the presence of a teacher or other member of staff trained and able to administer rescue medication. However, it is thought that the situation varies between schools and depends mainly on the goodwill and resources available locally.

Recommendations A more systematic response is needed to ensure that children receive rescue medication regardless of where their seizure occurs. Possible ways forward include: greater use of training resources for schools available from epilepsy voluntary sector organisations; consistent, practical information to schools; transparent guidance outlining a clear care pathway from the hospital to the school; and implementation and adherence to each child's individual healthcare plan. Implications Children requiring emergency treatment for prolonged convulsive seizures during school hours test the goals of integrated, person-centred care as well as joined-up working to which the National Health Service (NHS) aspires. As changes to the NHS come into play and local services become reconfigured, every effort should be made to take account of the particular needs of this vulnerable group of children within broader efforts to improve the quality of paediatric epilepsy services overall.

\section{INTRODUCTION}

Significant shortfalls in service delivery for children with epilepsy have recently been reported in the UK. ${ }^{1}{ }^{2}$ A particularly vulnerable group are children who experience prolonged convulsive seizures, defined as seizures lasting $5 \mathrm{~min}$ or more. ${ }^{3}$ National Institute for Health and Clinical Excellence (NICE) guidelines ${ }^{4}$ recommend immediate treatment of children with such seizures to prevent progression to status epilepticus and neurological morbidity. ${ }^{56}$ Most seizures occur outside of the hospital setting. Children are often unconscious during prolonged convulsive seizures; thus, whether or not they receive their treatment in time depends on the presence of a caregiver trained and able to administer rescue medication. This paper explores the issues that arise from the discussion of administering

\section{What is already known on this topic}

- It is recommended that children who have prolonged convulsive seizures receive rescue medication as quickly as possible to avoid progression to status epilepticus.

- Most seizures occur outside of the hospital setting.

- Whether or not a child receives rescue medication in time depends on the presence of a trained caregiver.

\section{What this study adds}

- Whether or not a child receives rescue medication at school depends on the resources and training available at each individual school.

- Many schools will either rely on parents or call an ambulance whenever a prolonged seizure occurs, with clinical consequences for the child.

- Clear guidance linking educational and healthcare sectors is needed for all children to receive rescue medication for prolonged seizures regardless of where they occur.

rescue medication in mainstream schools in the UK in the hope of raising awareness of unmet needs in this area.

\section{PROLONGED CONVULSIVE SEIZURES IN CHILDREN}

Seizures that last more than $5 \mathrm{~min}$ are unlikely to stop on their own; ${ }^{7}$ thus, guidelines recommend that rescue medication (buccal midazolam or, if preferred or if buccal midazolam is unavailable, rectal diazepam) be administered for any convulsive seizure lasting $5 \mathrm{~min}$ or more in a community setting. ${ }^{4}$ Delays in treatment increase the risk of status epilepticus, ${ }^{8}$ which may result in possible cognitive deficits ${ }^{59}$ and even death. ${ }^{10}$

The NICE guidelines for the diagnosis and management of the epilepsies in primary and secondary care recommend that all relevant caregivers, who include parents, teachers and other school staff, receive dedicated training to be able to administer rescue medication as promptly as possible to children according to a prespecified protocol. ${ }^{4}$ Guidance on medicines management in mainstream schools also 
Box 1 Summary of recommendations in existing national guidance on the management of medicines in schools ${ }^{11}$

- Parents submit a request to the school for their child to receive prescribed medication as needed. They provide all the necessary medical information from the treating physician.

- An individualised healthcare plan is agreed among the parents, school head, local health service and school doctor or nurse (if available).

- This is supported by a school policy on the administration of medicines and/or epilepsy.

- Teachers (or other staff members) are asked to volunteer to take responsibility for administering the medication in question.

- They receive specific training to do so either from the school nurse or local health service.

exists within the educational sector; however, it is not specific to the situation of children with prolonged convulsive seizures, and thus recommendations are subject to interpretation (box 1). ${ }^{11-13}$

\section{ARE SCHOOLS OBLIGED TO ADMINISTER RESCUE MEDICATION TO CHILDREN?}

In the UK, children with epilepsy are considered disabled for the purposes of the Equality Act of 2010 and are thus protected from discrimination in terms of admission and participation in school activities. ${ }^{14}$ Under the Education and Inspections Act of 2006, schools must make all arrangements necessary to meet the needs of any child requiring medical assistance during school hours. ${ }^{15}$ However, it is not a legal requirement for school staff to administer medicines to children (this role is entirely voluntary). Most teachers' unions actively discourage their members from accepting responsibility for doing so claiming that this falls outside of their duty of care and that they may be liable if anything goes wrong. ${ }^{16} 17$

What happens in practice? Little published evidence exists on the experience of children who require rescue medication at school but the situation is thought to vary between schools. Insights from epilepsy specialists suggest that schools often react with panic and fear when faced with a child having a prolonged convulsive seizure. Fear of liability is a major barrier to overcome (PERFECT, data on file, 2012).

Some schools call an ambulance for every prolonged convulsive seizure that occurs at school, potentially causing treatment delays and subsequent complications for the child. ${ }^{18} 19$ Others may expect parents to be permanently on call in case their child experiences a seizure during school hours, forcing many parents to abandon full-time employment for the safety of their child. Both situations may threaten the social integration of the child and lead to stigmatisation.

Certain requirements must be met for the needs of these children to be addressed during school hours, the most important being training, clear information and communication, resources and accountability.

\section{TRAINING, INFORMATION, RESOURCES AND ACCOUNTABILITY}

Several studies point to inadequate training on epilepsy in schools. A survey of schools carried out by Epilepsy Action in 2012 found that over a quarter had not received any epilepsy training in the past 3 years. ${ }^{20}$ One in six teachers said that pupils with epilepsy at their school either did not have an individual healthcare plan or that they did not know if they had one.

Better information and communication to schools is the key. ${ }^{1}$ Charitable organisations, in particular Young Epilepsy, the Joint Epilepsy Council and Epilepsy Action, have played an essential role in providing helpful resources on rescue medication to parents and schools in the form of guidance, templates and training courses. ${ }^{21-23}$ But implementing training requires firm commitment from staff volunteering to be trained as well as the school. For example, the Joint Epilepsy Council recommends two full days of training within school settings to ensure competency. ${ }^{22}$

Resources outside of the educational system are also critical. NICE recommends that every child with a diagnosis of epilepsy should have a dedicated paediatric epilepsy specialist nurse (ESN) who acts as the liaison to the child's school and provides support and training in the child's home and school. ${ }^{4}$ Unfortunately, poor resourcing of paediatric ESNs is a longstanding issue, despite their proven role in reducing the number of admissions to hospital for children. ${ }^{24}$ In all, $47 \%$ of the paediatric epilepsy centres audited in the Royal College of Paediatrics and Child Health Epilepsy12 (2012) survey had no ESNs. ${ }^{1}$ Without a dedicated ESN, parents are left as the sole link between the health service and the educational system, yet they may lack the necessary skills and information to fulfil such a role.

The issue of accountability is also important. NICE guidelines recommend that only children who have had a previous episode of prolonged convulsive seizures should be prescribed rescue medication. The implication of this 'responsible prescribing' is that schools are only asked to invest in training to administer rescue medication when they have a pupil who is known to be at risk.

\section{THE WAY FORWARD}

Children requiring emergency treatment for prolonged convulsive seizures during school hours test the goals of integrated, person-centred care as well as joined-up working to which the National Health Service (NHS) aspires. Whether a child receives rescue medication at school currently depends mostly on the goodwill and resources available at each school. Consequently, some children are effectively denied their basic legal right to mainstream education, a clearly unacceptable situation.

This situation is not unique to the $\mathrm{UK}^{25}$ and some possible ways forward are suggested in box 2 . They include: greater use of training resources for schools available from epilepsy voluntary sector organisations; consistent, practical information to schools; transparent guidance outlining a clear care pathway from the hospital to the school; and implementation and adherence to each child's individual healthcare plan.

Of course, the recommendations outlined above are not only relevant to children with epilepsy. Lack of support from schools is thought to be the main reason why diabetes specialists refrain from prescribing certain forms of insulin to children in the UK. ${ }^{26}$ And across Europe, organisations representing the interests of children with asthma, diabetes, epilepsy and anaphylaxis have joined forces to campaign for greater recognition of the medical needs of children with these conditions in schools (eg, http://www.medicalconditionsatschool.org.uk).

It is important to recognise that inadequacies in the current system are due to lack of resources and unclear guidance as opposed to lack of good will or professionalism on the part of schools and healthcare professionals. There are many promising 
Box 2 Areas for improvement in the management of children with prolonged seizures in schools

- Treating specialists should work with voluntary sector organisations to provide clear and practical information to schools on prolonged convulsive seizures and rescue medication.

- Every child with a history of prolonged convulsive seizures should have an individual healthcare plan put in place at his or her school.

- A clear link should be established, ideally via an epilepsy specialist nurse, between the treating physician and the school for each child who requires rescue medication.

- All caregivers responsible for a child at risk of prolonged convulsive seizures should receive specific training on their rescue medication.

- Comprehensive guidance that spans across the health and educational sector is needed to ensure that children at risk of prolonged convulsive seizures are treated as quickly as possible regardless of where the seizure occurs.

- More empirical data are needed to gain a better understanding of the experience of children who experience prolonged convulsive seizures at school, including the perspective of teachers. The role played by emergency services also needs to be clarified.

Adapted from Wait et al..$^{25}$

examples of primary care trusts working together with local educational authorities to find workable and sustainable solutions. As changes to the NHS come into play and local services become reconfigured, every effort should be made to maintain such collaborations. And more needs to be done generally to plan good epilepsy services at the local level, a point made evident in the 2013 Epilepsy Action survey and raised subsequently in the House of Commons. ${ }^{2}$

Limited resources will be an ongoing issue. Yet somehow, we need to ensure that the needs of children at risk of prolonged convulsive seizures are met in a similar manner regardless of where they go to school. As was expressed by a group of parents of children with diabetes: 'Every child matters—or do they? ${ }^{27}$ For the sake of all children who require medical assistance at school, this is not a question we wish to be asking ourselves in years to come.

\author{
Author affiliations \\ ${ }^{1}$ UCL Institute of Child Health, Great Ormond Street Hospital NHS Foundation Trust, \\ London, UK \\ ${ }^{2}$ Young Epilepsy, Lingfield, UK \\ ${ }^{3}$ SHW Health Ltd, London, UK \\ ${ }^{4}$ Epilepsy, Sleep and Paediatric Neurophysiology Department, University Hospitals of \\ Lyon (HCL), Lyon, France \\ ${ }^{5}$ IRCCS, Institute for Pharmacological Research "Mario Negri", Milano, Italy \\ ${ }^{6} \mathrm{Hull}$ and East Yorkshire Hospitals NHS Trust, Hull, UK \\ ${ }^{7}$ Neuro-musculo-skeletal Research Unit, University of Leuven, Leuven, Belgium \\ ${ }^{8}$ Department of Clinical Pharmacology and Therapeutics, Faculty of Medicine and \\ Surgery, University of Malta, Msida, Malta \\ ${ }^{9}$ Epilepsy Research Group, Berlin, Germany \\ ${ }^{10}$ ViroPharma SPRL, Brussels, Belgium
}

Contributors This paper was drafted as part of the Practices in Emergency and Rescue medication For Epilepsy managed with Community administered Therapy (PERFECT) initiative, which aims to gain a better understanding of how prolonged acute convulsive seizures in children are managed in non-hospital settings across Europe. All coauthors are members of the PERFECT Steering Committee and have participated in developing the study methodology and interpretation of findings. A first draft of this manuscript was written by SW and was reviewed by all other coauthors. HC is the guarantor of the paper.

Funding This paper was drafted as part of the Practices in Emergency and Rescue medication For Epilepsy managed with Community administered Therapy (PERFECT) initiative, which is funded by ViroPharma SPRL.

Competing interests We have read and understood the BMJ Group policy on declaration of interests and declare the following interests: Professor Cross holds an endowed Chair through University College, London. She is a member of the PERFECT steering committee and receives honoraria from ViroPharma SPRL for this role. She has sat on Advisory Boards for Eisai and ViroPharma and also sits on a safety monitoring board for GlaxoSmithKline for which honoraria are paid to UCL-ICH Neurosciences Unit. She worked as Clinical Advisor to the update of the NICE guidelines on the diagnosis and management of the epilepsies (2009-2012) and currently as Clinical Advisor to the Children's Epilepsy Surgery Service for which remuneration was and is made to her department. She is a recipient of research grants from Action medical Research, Great Ormond Street Hospital Charity and Epilepsy Research UK. Suzanne Wait is Director of SHW Health Limited and receives consultancy fees from ViroPharma SPRL. She is a member of the PERFECT steering committee. Alexis Arzimanoglou is Director of the Epilepsy, Sleep and Paediatric Neurophysiology department, University Hospitals of Lyon (France). He is a member of the PERFECT steering committee and receives honoraria from ViroPharma SPRL for this role. In the past 36 months, he has received speaker's or consultancy fees from Cyberonics, Eisai, GlaxoSmithKline, UCB Pharma and ViroPharma. He also sits on a safety monitoring board for UCB and received educational and European Community grants for which remuneration was made to $\mathrm{HCL}$ or to a research association of his department. Ettore Beghi serves on the editorial advisory boards of Epilepsia, Amyotrophic Lateral Sclerosis, Clinical Neurology \& Neurosurgery, and Neuroepidemiology. He is a member of the PERFECT steering committee and receives honoraria from ViroPharma SPRL for this role. He has received funding for travel and speaker honoraria from UCB-Pharma, Sanofi-Aventis, GSK, EISAI; funding from GSK for educational presentations; and from AIFA, Sanofi-Aventis, Janssen-Cilag, EISAI, Lombardy Region, Istituto Superiore di Sanità and American ALS Association for the coordinating activity of RCTs and observational study protocols. Christine Bennett has no conflicts of interest. She is a member of the PERFECT steering committee and receives honoraria from ViroPharma SPRL for this role. Lieven Lagae has received consultancy honoraria from ViroPharma and is a member of the PERFECT steering committee, for which he receives honoraria from ViroPharma SPRL. Dr Janet Mifsud has received consultancy honoraria from ViroPharma during the past year. She is a member of the PERFECT steering committee and receives honoraria from ViroPharma SPRL for this role. Professor Dieter Schmidt is a member of the PERFECT steering committee and receives honoraria from ViroPharma SPRL for this role. He has received hospitality, speaker fees or consultancy honorarium from ViroPharma, GSK, Sun Pharma, Novartis and UCB Pharma during the past year. Gordon Harvey is an employee of ViroPharma SPRL and is a member of the PERFECT steering committee.

Provenance and peer review Not commissioned; externally peer reviewed.

Data sharing statement This paper was drafted as part of the Practices in Emergency and Rescue medication For Epilepsy managed with Community administered Therapy (PERFECT) initiative. This paper draws from the first two phases of PERFECT: a review of clinical guidelines and non-clinical guidance relevant to the management of prolonged seizures in children in non-hospital settings, which has been published (Wait et al, Eur J Paediatr Neurol $2013^{25}$ ), and a survey of physicians who treat children with prolonged seizures (publication in press). A third phase consisting of a survey of children with prolonged seizures and their parents will report and be published in full in early 2014.

Open Access This is an Open Access article distributed in accordance with the Creative Commons Attribution Non Commercial (CC BY-NC 3.0) license, which permits others to distribute, remix, adapt, build upon this work non-commercially, and license their derivative works on different terms, provided the original work is properly cited and the use is non-commercial. See: http://creativecommons.org/ licenses/by-nc/3.0/

\section{REFERENCES}

1 Royal College of Paediatrics and Child Health. Epilepsy12: United Kingdom collaborative clincial audit of health care for children and young people with suspected epileptic seizures, National report. London: Royal College of Paediatrics and Child Health, 2012.

2 Epilepsy Action. A Critical Time for epilepsy in England. A study of epilepsy service provision in England by Epilepsy Action. Epilepsy Action 2013.

3 Pellock JM. Overview: definitions and classifications of seizure emergencies. J Child Neurol 2007:22:9S-13S.

4 National Institute for Health and Clinical Excellence. The epilepsies: the diagnosis and management of the epilepsies in adults and children in primary and secondary 
care. NICE clinical guideline 137. London: National Institute for Health and Clinical Excellence, 2012.

5 Chin R, Neville B, Peckham C, et al. Incidence, cause and short-term outcome of convulsive status epilepticus in childhood: prospective population-based study. Lancet 2006;368:222-9.

6 Shinnar S, Hesdorffer DC, Nordli D Jr, et al. Phenomenology of prolonged febrile seizures: results of the FEBSTAT study. Neurology 2008;71:170-6.

7 Shinnar S, Berg AT, Moshe SL, et al. How long do new onset seizures in children last? Ann Neurol 2001;49:659-64.

8 Shinnar S. Who is at risk of prolonged seizures? J Child Neurol 2007;22:14S-9S.

9 Sheppard E, Lippe S. Cognitive outcome of status epilepticus in children. Epilepsy Res Treat 2012;2012:984124. doi:10.1155/2012/984124. Epub 2012 Aug 13.

10 Arzimanoglou A. Outcome of status epilepticus in children. Epilepsia 2007;48:91-3

11 Department for Education. Managing medicines in schools. London: Department for Education, 2005

12 Northern Ireland Department of Education and Department of Health. Supporting pupils with medication needs. Belfast: Northern Ireland Department of Education and Department of Health, 2008.

13 Scottish Executive. The administration of medicines in schools. Glasgow: Scottish Executive, 2001.

14 Equality Act, UK. 2010

15 Education and Inspections Act of 2006, UK.
16 National Union of Teachers. Administration of medicines. Health and safety briefing. London: National Union of Teachers, 2011.

17 UNISON. Managing medicines and providing medical support in schools and early years settings. UNISON branch advice. London: UNISON, 2011.

18 Chin R, Verhulst L, Neville B, et al. Inappropriate emergency management of status epilepticus in children contributes to need for intensive care. J Neurol Neurosurg Psychiatry 2004;75:1584-8.

19 Tirupathi S, McMenamin JB, Webb DW. Analysis of factors influencing admission to intensive care following convulsive status epilepticus in children. Seizure 2009;18:630-3

20 EpilepsyAction. EpilepsyAction 2012 Schools' Survey. 2012

21 Epilepsy Action. Epilepsy policy for schools. 2009.

22 Joint Epilepsy Council. A Guideline on Training Standards for the Administration of Buccal Midazolam. 2012.

23 Champions for Childhood Epilepsy Campaign training DVD. 2011.

24 Epilepsy Action. Epilepsy in England: time for change. A study of epilepsy service provision in England by Epilepsy Action. 2009.

25 Wait S, Lagae L, Arzimanoglou A, et al. The administration of rescue medication to children with prolonged acute convulsive seizures in the community: what happens in practice? Eur J Paediatr Neurol 2013;17:14-23.

26 Edge J. Insulin injections in schools. Arch Dis Child 2009;94:412-13.

27 UK Children With Diabetes Advocacy Group. Every child matters: or do they? Children with type 1 diabetes are being let down by lack of support in school. 2007. 